\title{
Low Dosage of DDS
}

\author{
D. L. LEIKER* and D. CARLING, м.в., сн.в., D.т.м.н.
}

Preliminary report on progress of lepromatous patients on low and high dosages.
D. L. Leiker ${ }^{1}$
D. Carling ${ }^{2}$
J.J. Spaas ${ }^{3}$
N. Ziedses des Plantes

The maximum dosage of DDS in leprosy clinics in Northern Nigeria supervised by Government was $600 \mathrm{mg}$, once weekly. Recently the maximum dosage was reduced to $400 \mathrm{mg}$ weekly. In some clinics supervised by voluntary agencies the maximum dosage was $800 \mathrm{mg}$ DDS weekly. At present in most clinics the Government scheme is adopted. The general impression was that the incidence of reactions was higher in clinics with a high dosage scheme, and that progress of the patients was not better than in Government clinics.

In many Government clinics on the average $5^{0}-60$ per cent of the patients attend very regularly. Such patients receive an average weekly dosage of $500-600 \mathrm{mg}$ DDS. About 20 per cent of the patients attend less regularly, but still fairly regularly, and they receive not more than an average dosage of $200-400 \mathrm{mg}$ DDS weekly. The bacteriological status of several hundred lepromatous patients who had been on treatment for several years was compared. It was found that the bacteriological index did not differ greatly in very regularly attending and fairly regularly attending patients after a comparable number of years of treatment. The bacteriological index was however significantly higher in those who had attended very irregularly. These findings suggested the possibility that a lower dosage of DDS might be as effective as a higher dosage. Therefore a limited pilot trial was initiated in the Bornu Provincial Leprosy Settlement at Molai.

A number of lepromatous cases with a high bacteriological index was selected. The patients were examined by the first two authors. Borderline cases and borderline lepromatous cases were excluded from the trial. The register numbers of the patients were written on pieces of paper. The papers were thoroughly mixed and thereafter the first number that was drawn, was put in group I, for $200 \mathrm{mg}$ DDS weekly, the second number in group 2 for $400 \mathrm{mg}$ DDS weekly and the third number in group 3 for $800 \mathrm{mg}$ DDS weekly, etc. Six smears were taken monthly. The average bacteriological index of the smears of two months are given in table I.

At the beginning of the trial, and furthermore every three months a punch biopsy specimen was taken from one lesion, the next one as near as possible to the previous one. The biopsies were kept until the end of the trail and then processed in one period in order to avoid differences in staining technique as much as possible.

Assessment was made by counting bacilli (bacillery index), by counting the percentage of intact bacilli and by measuring the percentage of the section affected by infiltration. The examiner did not know the patient whose sections were examined, nor the group to which the patient belonged. These three data are also given in table I.

In group I and 3 a number of patients reacted repeatedly and severely. Such patients have received much less than the scheduled dosage. The groups therefore were subdivided into a group of patients who had no reactions or only one or two reactions and a group of patients with four or more reactions.

Between the group of patients on $200 \mathrm{mg}$ and those on $800 \mathrm{mg}$, who had only few reactions, no marked difference in decrease of bacillary index was found. The decrease in percentage of intact bacilli was more marked in the $200 \mathrm{mg}$ group. The decrease in percentage of the sections that is affected by infiltration is of the same order.

* I Dermatologist, Royal Tropical Institute, Amsterdam, Netherlands, formerly specialist leprologist Ministry of Health, Northern Nigeria.

2 Medical Superintendent, Bornu Provincial Leprosy Settlement, Molai, N. Nigeria.

3 Pathologist, Central Pathological Laboratory, 'Dijkzigt', Rotterdam, Netherlands.

Low Dosage of DDS 
T A B L E I

\section{Group I - 200 m. DDS}

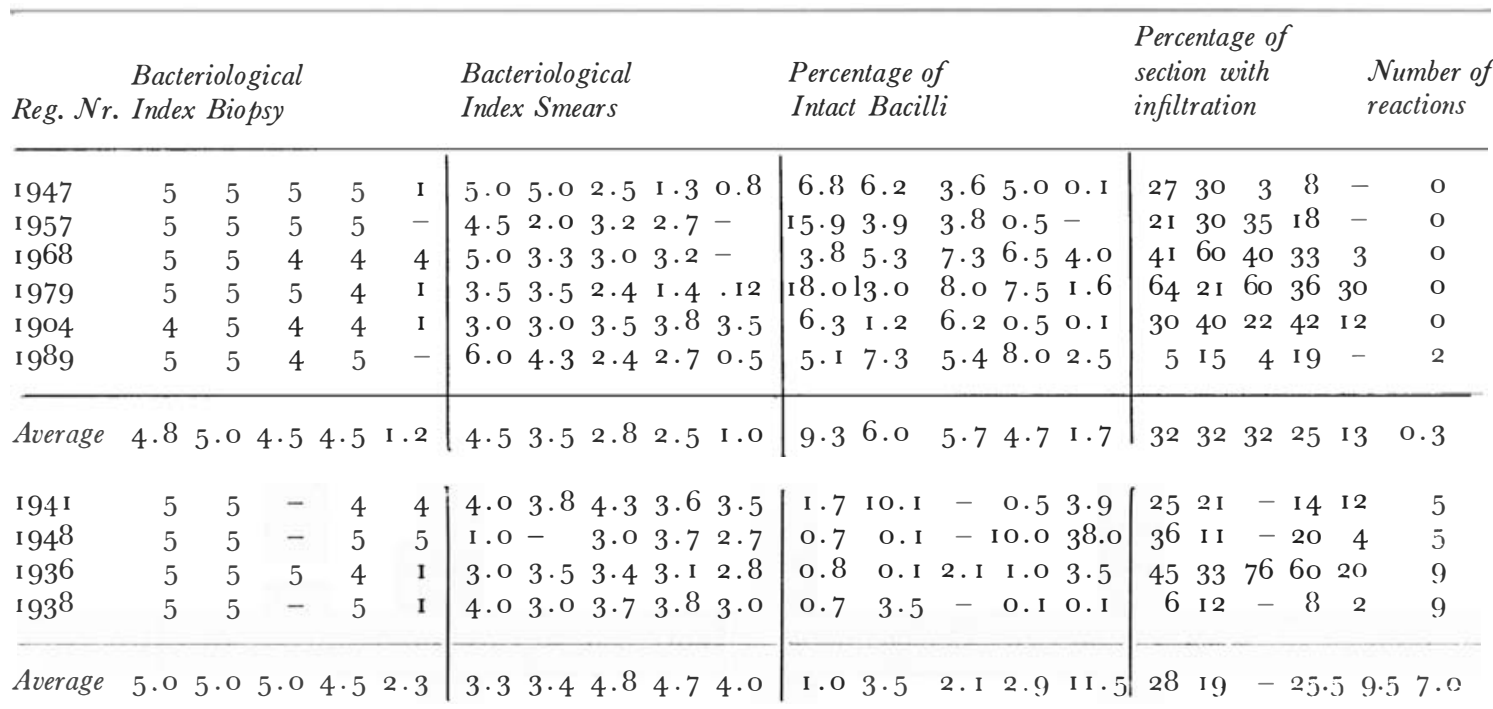

\section{Group II - 400 mg. DDS}

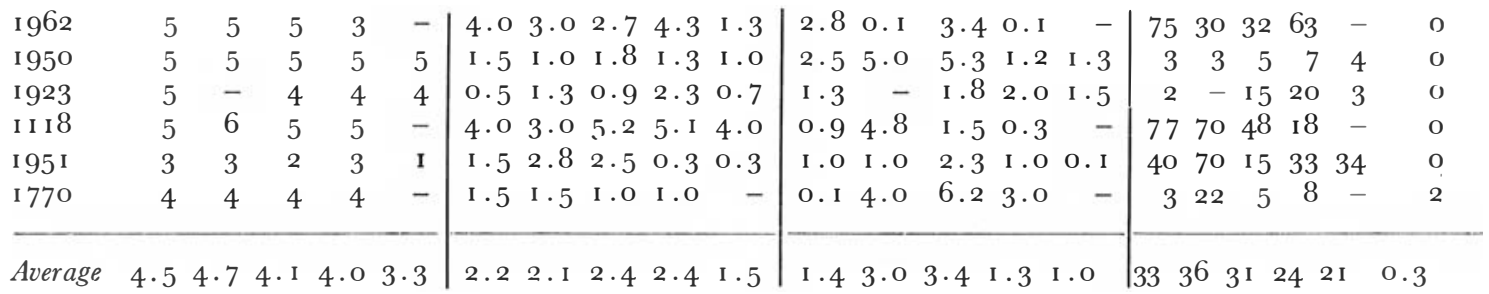

\section{Group III - 800 mg. DDS}

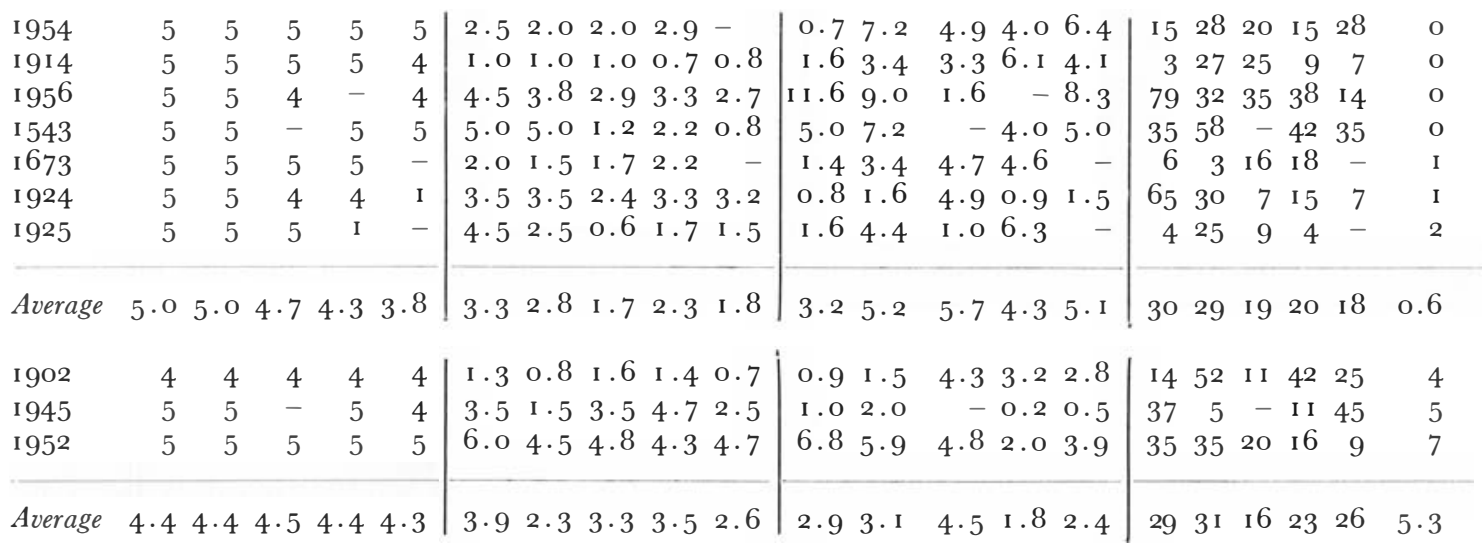
28 Leprosy Review 
Progress was in all aspects less good in the group of patients with repeated reactions, despite the much lower dosage received by these patients.

From this limited trial it seems that the lower dosage of $200 \mathrm{mg}$ DDS weekly is not less effective and may even be on the average more effective than the higher dosages. The method of assessment in this trial is regarded as more reliable than the usual method of evaluation of smears only. However, because of the limited number of patients on trial, no final conclusions are drawn, but the trial will be continued with a large group of patients on less than Ioo $\mathrm{mg}$ and $600 \mathrm{mg}$ DDS respectively, for a longer period.

S UM M AR Y

The assessment of biopsies and smears from a series of lepromatous patients on treatment with $200 \mathrm{mg}$, $400 \mathrm{mg}$ and $800 \mathrm{mg}$ DDS once weekly, strongly suggests that the lower dosage is on the average at least as effective, as the higher dosage. A larger trial series is needed for conclusive evidence. 